\title{
Progress in Chemical Compositions and Pharmacological Activities of FlosPopuli
}

\author{
Junyan Chu, ${ }^{a}$ Yingying $\mathrm{Fu}^{2}{ }^{a}$ and Jifeng $\mathrm{Liu}^{*, a, b}$ \\ ${ }^{a}$ School of Pharmaceutical Sciences, Institute of Drug Discovery and Development, Key Laboratory of \\ Advanced Pharmaceutical Technology, Ministry of Education of China, Zhengzhou University, \\ Zhengzhou, Henan 450001, China \\ ${ }^{b}$ Collaborative Innovation Center of New Drug Research and Safety Evaluation, Zhengzhou, \\ Henan 450001, China \\ Email: liujf2009y@126.com (J. L.)
}

\begin{abstract}
FlosPopuli is a dry male inflorescence of Populus tomentosa., Populus canadensis. Some researches show that FlosPopuli contains rich flavonoids and phenolic glycosides, which have antibacterial, anti-inflammatory, anti-oxidant and anti-viral effects. In order to systematically understand the chemical compositions and biological activities of FlosPopuli and lay the foundation for subsequent research, this article reviews the two above aspects. Fifty-three kinds of flavonoids, phenol glycosides and others were isolated from FlosPopuli; moreover, their antibacterial, anti-inflammatory and hypolipidemic effects were investigated.
\end{abstract}

Keywords FlosPopuli, flavonoids, antibacterial, chemical components, activities

\section{Introduction}

FlosPopuli is a dry male inflorescence of Populus tomentosa. ( $P$. tomentosa.), Populus canadensis ( $P$. canadensis) or several plants of the same genus, which is widely distributed in Liaoning, Shanxi, Hebei and Gansu provinces of China. ${ }^{[1,2]}$ It is bitter and slightly cold, and taken to clear away heat and toxins, and eliminate dampness and reduce diarrhea. FlosPopuli is mostly used as a folk medicine for bacterial dysentery, diarrhea of young animals, etc. It is also applied for treating urticaria and itching of the skin. FlosPopuli is easy to obtain, low in price and yet high in medicinal value. Because of its widespread distribution, the research on active ingredients was carried out as far back as in 1976. Some studies showed that the main antibacterial components of FlosPopuli were flavonoids, polysaccharides, glycosides, phytosterols, terpenes, amino acids, tannins, and volatile oils. ${ }^{[3]}$ This article reviews the research papers on FlosPopuli from 1976 and lays the foundation for subsequent research.

\section{Chemical Constituents}

A total of 53 flavonoids, glycosides, phytosterols, esters and other compounds were isolated from the dried male inflorescence of FlosPopuli.

\section{Flavornoids}

Flavonoids are the main antibacterial active ingredients in FlosPopuli. Chrysoeriol (1), apigenin (2), luteolin (3), dillenetin (4), kaempferol (5), quercetin (6), myricetin (7), rhamnzin (8), pinocembrin (9), naringenin (10), isosakuranetin (11), eriodictyol (12), taxifolin (13), dihydromyricetin (14), pinostrobin (15), galangin-3-methoxy (16), chrysin (17), puercetin-3,7-dimethoxy (18), rhamnetin (19) and kaempferol-3-methoxy (20) were isolated. Among them, compounds 1, 4, 7, 8, 10-14 and 18 were obtained from this plant for the first time (Figure 1). ${ }^{[4-9]}$

In recent years, the following phenol glycosides have been isolated from FlosPopuli: apigenin-7- $O-\beta$ - $D$-glucopyranoside (21), luteolin-7-O- $\beta$ - $D$-glucopyranoside (22), diosmetin-7- $O-\beta$ -

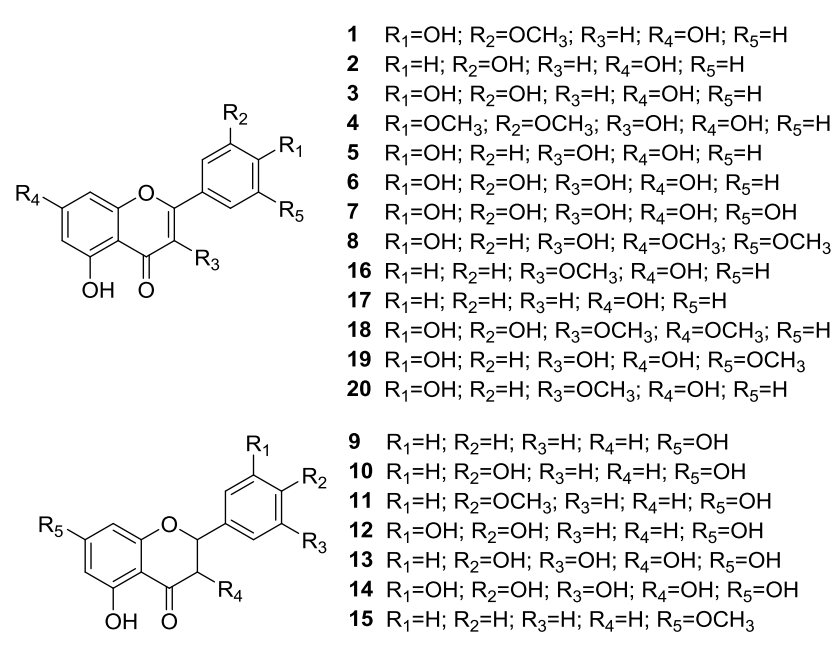

Figure 1 Flavornoids isolated from FlosPopuli.

$D$-glucopyranoside (23), kaepferide-7-O- $\beta$ - $D$-glucopyranoside (24), 5-hydroxy-flavanone-7-O- $\beta$ - $D$-glucopy-ranoside (25), kempferol-3-O-\{[2-O- $\alpha$ - L-rhamnopy-ranosyl-4-O- $\beta$ - $D$-glucopyranosyl]- $\beta$ - $D$-glucopyranoside\} (26), apigenin-7-O-(-6"-O-p-coumaroyl)- $\beta$ - $D$-glucopyranoside (27), syringin (28), salicin (29), benzylalcohol-O- $\beta$ - $D$-glucopyranoside $(\mathbf{3 0})$, tremulacin $(\mathbf{3 1})$, salireposide (32), 2-hydroxycyclohexyl-6'-O- $p$-coumaroyl- $\beta$ - $D$-glucopyranoside (33), Daucosterol (34), 2-methyl-1,3,6-trihydroxy$9,10$-anthraquinone-3-O-(6'-O-acetyl)- $\alpha$-rhamnosyl-( $1 \rightarrow 2)-\beta$ - $D$ glucoside (35), 2-methyl-1,3,6-trihydroxy-9,10-anthraquinone3-O- $\alpha$-rhamnosyl $(1 \rightarrow 2)-\beta$ - $D$-glucoside (36), (2S)-5,7-dihydroxyflavanone-7-O- $\beta$ - $D$-glucopy-ranoside (37), apigenin-7-O- $\beta$ - $D$ (-6"-pcoumaroyl)-glucoside (38), chrysoeriol-7-O- $\beta$ - $D$-glucopyranosid (54), 2-acetyl-1,3-diacaffeoylglycerol (55). Among them, compounds $\mathbf{2 1}, \mathbf{2 3}, \mathbf{2 5}, \mathbf{2 8}, \mathbf{3 0}$ and $\mathbf{3 3}$ were obtained from this plant for the first time (Figure 2). ${ }^{[6-8,10,27]}$ 


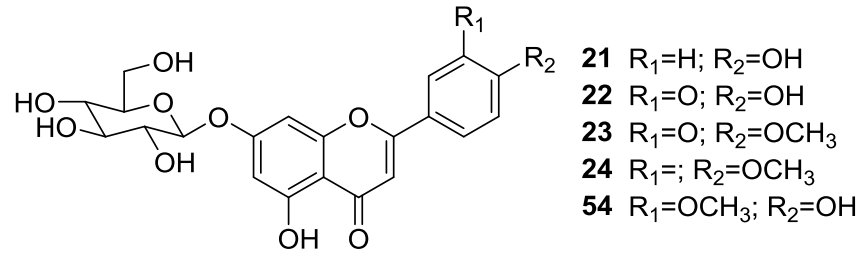<smiles>O=c1cc(-c2ccccc2)oc2cc(OC3OC(O)C(O)C(O)C3CO)cc(O)c12</smiles>

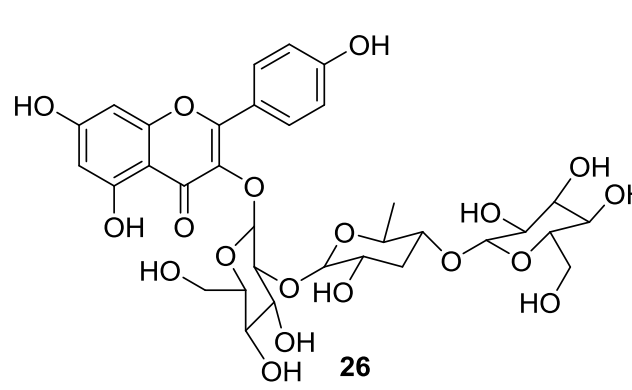<smiles>O=C(/C=C/c1ccc(O)cc1)OCCC(O)(COc1cc(O)c2c(=O)cc(O)oc2c1)C(O)CO</smiles><smiles>COc1cc(/C=C/CO)cc(OC)c1OC1OC(CO)C(O)C(O)C1O</smiles><smiles>OCc1ccccc1OC1OC2(CO)C(O)C(O)C1(O)C(O)C2O</smiles>

29<smiles>OCC1(CO)OC(Oc2ccccc2)C(O)C(O)C1O</smiles>

30<smiles>O=C(OCC(CO)(CO)C(O)C(O)COc1ccccc1COC(=O)C1(O)C=CCCC1=O)c1ccccc1</smiles>

31<smiles>O=C(OCc1ccccc1OCCC(O)CCO)c1ccccc1</smiles>

32

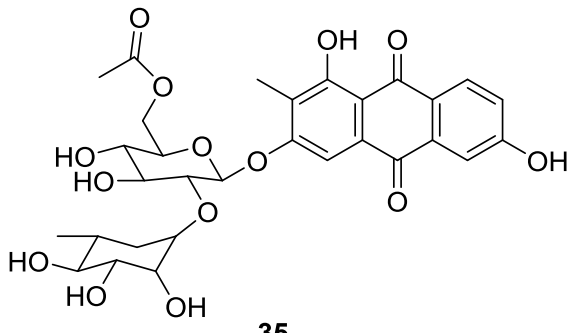

35<smiles>CC(C)(C)c1cc(OC(O)CC(O)C(O)C(O)COC(=O)/C=C/c2ccc(O)cc2)cc2oc(-c3ccc(O)cc3)cc(=O)c12</smiles><smiles>O=C(/C=C/c1ccc(O)cc1)OC1OC(CO)C(O)C(O)C1O</smiles>

Figure 2 Polysaccharides and glycosides isolated from FlosPopuli. 
<smiles>CC[C@H](CC(C)C)[C@H](C)C1CC[C@H]2[C@@H]3CC=C4CC(O)CC[C@]4(C)[C@H]3CC[C@]12C</smiles>

39<smiles>C=C(C)[C@H]1CCC2(C(=O)O)CC[C@H]3C(CCC4[C@@]3(C)CCC3C(C)(C)C(=O)CC[C@@]34C)C12C</smiles>

42<smiles>O=C(OCCCCO)C(O)C(O)CCOc1ccccc1CO</smiles>

45<smiles>O=C(O)c1ccc(O)c(O)c1</smiles>
48<smiles>Oc1ccccc1O</smiles>

51<smiles>CCC(C[C@H](C)C1CCC2[C@H]3CC=C4CC(O)CC[C@]4(C)[C@H]3CC[C@]12C)C(C)C</smiles>

40

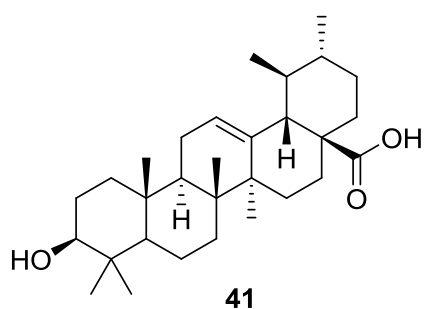<smiles>COC(=O)/C=C/c1ccc(OC)c(O)c1</smiles>

43<smiles></smiles>

46<smiles>O=C(O)C=Cc1ccc(O)c(O)c1</smiles>

49<smiles>O=C(/C=C/c1ccc(O)cc1)OC1OC(O)C(O)C(O)C(O)C1O</smiles>

44<smiles>O=C(O)/C=C/c1ccc(O)cc1</smiles>

47<smiles>O=C1c2ccccc2C(=O)c2c(O)cc(O)cc21</smiles><smiles>Oc1ccc(-c2ccc(O)c(O)c2)cc1O</smiles>

52<smiles>CC(=O)OC(COC(=O)/C=C/c1ccc(O)c(O)c1)COC(=O)/C=C/c1ccc(O)c(O)c1</smiles>

53

Figure 3 Other compounds isolated from FlosPopuli.

\section{Other compounds}

Li et al. ${ }^{[10]}$ mentioned that phytosterols and triterpenes were isolated from FlosPopuli: $\gamma$-sitosterol (39), $\beta$-sitosterol (40), ursolic acid (41), betulonic acid (42). Four lipids were isolated: methylisoferulate (43), $p$-coumaric acid glucoside (44), tremuloidine (45), and 4'-hydroxy-1'-O-( $\beta$ - $D$-glucoside)-benzyl-2hydroxy-benzoate (46). Three phenylpropanoids: coumaric acid (47), protocatechuic acid (48), caffeic acid (49) and other compounds xanthopurpurin (50), catechol (51), 3,3',4,4'-tetrahydroxybphenyl (52), 2-acetyl-1,3-dicaffeoylgly-cerol (53) were isolated. Among them, compounds 41, 42, 46, 48, 51-53 were obtained from this plant for the first time (Figure 3). ${ }^{[4-9]}$

In addition, Zhao et al. ${ }^{[13]}$ used a pre-column derivative
RP-HPLC to identify 21 amino acids from FlosPopuli. The total amount of free amino acids was $1630.47 \mathrm{mg} / 100 \mathrm{~g}$, and the total amount of amino acids after hydrolysis was 16386.74 $\mathrm{mg} / 100 \mathrm{~g}$. He et al. ${ }^{[12]}$ extracted volatile components from $P$. tomentosa. by using distillation extraction method, and isolated and identified 35 volatile components by GC/MS/DS. ${ }^{[11]}$

\section{Pharmacological Activities}

FlosPopuli in the early days was used to treat animal diarrhea, with the function of clearing heat and detoxifying, removing dampness and stopping dysentery. As early as recorded in the "Compendium of Materia Medica" that: "Rinse stewed FlosPopuli to relief the toothache, take it to detoxify the arsenic, burn it to ash and then mix with oil to heal empyrosis." 


\section{Elimination of free radicals}

$\mathrm{Li}$ et al. ${ }^{[14]}$ measured the elimination effect of male inflorescence extract of $P$. tomentosa on active oxidative free radicals of $\mathrm{O}_{2}^{-}, . \mathrm{OH}, \mathrm{H}_{2} \mathrm{O}_{2}$ by chemiluminescence and colorimetry. The results showed that the flavonoid extracts from male inflorescence of FlosPopuli had an obvious elimination effect on free radicals of $\mathrm{O}_{2}^{-}, \cdot \mathrm{OH}$ and $\mathrm{H}_{2} \mathrm{O}_{2}$ in vitro. The experimental results showed that the $\mathrm{IC}_{50}$ for $\cdot \mathrm{O}_{2}{ }^{-}$radical was $0.217 \mathrm{mg} / \mathrm{mL}$. As the flavonoid concentration of FlosPopuli male inflorescence increased, the $\mathrm{O}_{2}{ }^{-}$clearance rate continued to increase. The $\mathrm{IC}_{50}$ for the $\cdot \mathrm{OH}$ radical was $0.606 \mathrm{mg} / \mathrm{mL}$, and there was also a dose-effect relationship between its concentration and clearance, which is equivalent to 0.100 $\mathrm{mg} / \mathrm{mL}$ of quercetin and it could significantly inhibit DNA damage caused by $\cdot \mathrm{OH}$. When examining the scavenging rate of $\mathrm{H}_{2} \mathrm{O}_{2}$ free radicals, it was found that the inflorescence flavones of $P$. tomentosa can obviously inhibit the chemiluminescence of the system, and the luminescence value decreased significantly with the increasing of flavonoid concentration, and its $\mathrm{IC}_{50}$ was $0.061 \mathrm{mg} / \mathrm{mL}$. The results showed that the extract from male inflorescence of $P$. tomentosa had a good scavenging effect on $\mathrm{H}_{2} \mathrm{O}_{2}$ free radicals, or it could compete for the energy of $\mathrm{H}_{2} \mathrm{O}_{2}$ free radicals or both of them. ${ }^{[10,23]}$

Tang et al. ${ }^{[15]}$ further investigated the antioxidant capacity of FlosPopuli alcohol extracts and found that alcohol extracts had a remarkable scavenging effect on DPPH free radicals. As the concentration increased, the scavenging capacity of alcohol extract from free radical in FlosPopuli also increased significantly, showing a positive correlation. The concentration of $\mathrm{IC}_{50}$ was $36.40 \pm 0.62 \mu \mathrm{g} / \mathrm{mL}$, which was equivalent to the $\mathrm{IC}_{50}$ of vitamin $\mathrm{C}$. At the same time, it had strong reducing ability, and the $E_{50}$ was $206.32 \pm 1.61 \mu \mathrm{g} / \mathrm{mL}$.

\section{Antibacterial effect}

Zhou et al. ${ }^{[18]}$ disclosed that the ultrasonic extract of FlosPopuli had a strong inhibitory effect on E.coli and Salmonella in vitro by MIC assay. The results showed that the MIC of E.coli and Salmonella were 16-64 $\mathrm{mg} / \mathrm{mL}$ and $64-128$ $\mathrm{mg} / \mathrm{mL}$, respectively. The antibacterial effect on E.coli was better than Salmonella. Fang et al. ${ }^{[28]}$ compared MIC values of ethyl acetate and $n$-butanol extracts of FlosPopuli extracts with other types of Chinese herbal medicines against E.coli and Salmonella. They found that the antibacterial effect of FlosPopuli was better than that of Atractylodeslobata, Houttuynia cordata, Honeysuckle, Cork, Isatis root, Dandelion and Forsythia. The main components possessing antibacterial activities might be flavonoids and phenolic glycosides.

By measuring the inhibitory effect of FlosPopuli on pathogenic pig-derived E.coli, Wang et al. ${ }^{[19]}$ obtained MIC of 0.0039 $\mathrm{g} / \mathrm{mL}$ and $\mathrm{MBC}$ of $0.03125 \mathrm{~g} / \mathrm{mL}$, which indicated that it had an obvious inhibitory effect on E.coli from pigs, and also on E.coli from chickens and rabbits.

In order to observe the effect of FlosPopuli on chicken vibrios hepatitis, Chen et al. ${ }^{[20]}$ dissolved the extracts of FlosPopuli into water, and three different concentrations were administered once per day for three consecutive days, with cefotaxime sodium as the control group. It was found that the cure rate of water dilutions of $100 \mathrm{~g} / 500 \mathrm{~kg}$ for Vibrio hepatitis in chicken was more than $80 \%$. $^{[17-21,25-26]}$

\section{In vitro cytotoxicity}

Hou et al. ${ }^{[8]}$ reported that the flavonoids luteolin, quercetin, pinocembrin, and xenophytin extracted from FlosPopuli had significant inhibitory effects on vitro cells, of which luteolin and quercetin exhibited significant inhibitory effects on human liver cancer cell line HepG2, human hepatoma cell line Hela, and human normal hepatocyte line L02. The $\mathrm{IC}_{50}$ of luteolin on the three cell lines was $5.79 \pm 2.55 \mu \mathrm{g}$, and allopidin had significant inhibitory effects on human hepatoma cell line HepG2 with $\mathrm{IC}_{50}$ of $13.50 \pm 2.59 \mu \mathrm{g} / \mathrm{mL}$ and $9.13 \pm 2.56 \mu \mathrm{g} / \mathrm{mL}$.

\section{Anti-inflammatory effect}

Hou et al. ${ }^{[8]}$ studied the anti-inflammatory activity of FlosPopuli extracts by MTT method and found that tremulacinand 2-acetyl-1,3-dicaffeoylglycerol extracted from FlosPopuli had inhibitory effects on TNF- $\alpha$, IL-6, IL-1 $\beta$ and other related inflammatory factors. Among them, the anti-inflammatory effect of tremulacin may be related to the inhibition of the expression of related inflammatory cytokines TNF- $\alpha$, IL-6 and $\mathrm{IL}-1 \beta$, and the anti-inflammatory effect of 2-acetyl-1,3-dicaffeoylglycerol might be related to the down-regulation of TNF- $\alpha$, IL-6, IL-1 $\beta$ and other related inflammatory cytokines in cells, but the underlying mechanism of their anti-inflammatory effects remain to be discovered.

\section{Hypolipidemic effect}

Tang et al. ${ }^{[15]}$ treated hyperlipidemic mice (induced by a high-fat) with FlosPopuli extract by enema. They found that compared with the control group, the levels of TC, TG, and LDL-C in both the prevention group and the treatment group were significantly lower, while the levels of HDL-C were significantly increased. This suggested that the extract of FlosPopuli had a hypolipidemic effect. ${ }^{[26]}$

\section{Antidiarrheal effect}

$\mathrm{Xu}$ et al. ${ }^{[22]}$ experimentally determined the effect of water extract of FlosPopuli (FPAE) on castor oil-induced diarrhea in mice. They found that FPAE $(100-500 \mathrm{mg} / \mathrm{kg}$, p.o.) had dose-dependent and significantly protective effects against castor oil diarrhea in mice. Delayed onset of diarrhea induced by castor oil, reducing the frequency and severity of diarrhea, total stool, wet stool number, wet weight, and so on, were improved compared to control mice. In addition, FPAE significantly reduced the normal intestinal push and transport, compared to berberine hydrochloride, but lower than morphine. They also found that FPAE did not show any acute toxicity. When the concentration was lower than $5 \mathrm{~g} / \mathrm{kg}$, FPAE did not cause any death or change the normal behavior of animals.

\section{Impact on immune function}

$\mathrm{Li}$ et al. ${ }^{[24]}$ compared the effects of water extracts and alcohol extracts of FlosPopuli on the immune function of mice. They disclosed that both water and alcohol extracts could significantly improve the spleen and thymus index, phagocytic capacity and tlymphocytes of normal mice. Proliferative capacity, delayed allergic levels, cellular and humoral immune functions and the effects of alcohol extracts were significantly higher than those of water extracts, which might be related to the higher content of flavonoids, polysaccharides and other immune substances in alcohol extracts. However, the effect of different components in different extracts on immune function needs to be further explored.

\section{Conclusion and Perspective}

In summary, FlosPopuli is widely distributed in China, which is cheap and easy to obtain. With the efforts done by researchers, the chemical components have been isolated including flavonoids, polysaccharides and glycosides, sterols and triterpenes, phenylpropanoids and other types, as well as various amino acids and volatile components. FlosPopuli extract has also been employed in a variety of pharmacological activities, including antioxidant, antibacterial, cytotoxic, anti-inflammatory and hypolipidemic effects. Nevertheless, the research on the mechanism of its biological activities is very 
limited, which greatly hinders its application. Therefore, it is necessary for us to further study the chemical compositions, pharmacological activities and mechanism of action of FlosPopuli for better utilization of the resource.

\section{Acknowledgement}

This work was supported by the Science and Technology Tackling Project of Henan Science and Technology Department. (No. 182102310063) and the Key Scientific Research Project in University of Henan Province (No. 17A350013)

\section{Conflict of Interest}

The authors declare no conflict of interest.

Copyright ( $\odot 2020$ Junyan Chu, Yingying Fu, Jifeng Liu. This article is an open access article distributed under the terms and conditions of the Creative Commons Attribution (CC BY) license (http://creativecommons.org/licenses/by/4.0/). The use, distribution or reproduction in other forums is permitted, provided the original author(s) or licensor are credited and that the original publication in this journal is cited, in accordance with accepted academic practice. No use, distribution or reproduction is permitted which does not comply with these terms.

\section{References}

[1] Li, J. Z.; Han, Z. R.; Sun, H. M.; Xin, T. Studies on the chemical constituents of the FlosPopuli (Bulletin). J. Chin. Mater. Med. 1989, $1,43$.

[2] Li, C. S.; Zhao, Y. P. Application of FlosPopuli in feed production. Feed Res. 2015, 2, 29-31.

[3] The 72nd Graduation Practice of the Workers, Study on the effective part of FlosPopuli. J. Beijing Med. Coll. 1976, 1, 28-31.

[4] Liang, S. Y.; Zhang, Q. F. Studies on the chemical constituents of the FlosPopuli. Tradit. Chin. Med. Bull. 1988, 1, 41-42.

[5] Wang, X.; Wang, H.; Wang, Q.; Studies on chemical constituents of Populus Canadensis Moench. J. China Pharm. Univ. 2000, 3, 13-15.

[6] Hou, Y.; Zhang, G. J; Cui, H. M.; Liu, S. J.; Chen, L.; Li, B.; Dong, J. $X$. J. Chemical constituents from the male anthotaxy of Populus tomentosa Carr. Int. Pharm. Res. 2017, 44, 1131-1136.

[7] Hou, Y.; Li, B. W; Zhang, G. J.; Li, M.; Liao, X. Y.; Cui, H. M.; Xia, Z. M.; Tian, Y.; Liu, S. J.; Chen, L.; Li, B.; Dong, J. X. Isolation and Identification of Chemical Constituents of Populus tomentosa Male Inflorescence II. Chin. J. Exp. Tradit. Med. Formulae 2018, 24, 77-81.

[8] Hou, Y. Master Degree Dissertation, Study on the Chemical Constituents and Bioactivity from FlosPopuli. Anhui Medical University, Anhui, China, 2019.

[9] Wang, Y. P.; Dong, L.; Guo, S. J.; Shen, Z. Q.; Xu, Q. Q.; Zhang, Y.; Zhang, Z. M.; Zhou, C. F.; Yang, L. M. Studies on the species and pharmacology of flavonoid in the FlosPopuli. Heilongjiang J. Anim. Sci. Vet. Med. 2012, 8, 97-98.

[10] Li, F. W. Master Degree Dissertation, Study on Chemical Constituents of male anthotaxy of Populus tomentosa Carr. Shandong Agricultural University, Shandong, China, 2005.

[11] He, F. Y.; Zhang, J. L.; Li, T. C.; Hou, D. Y. GC/MS Analysis of volatile components in the FlosPopuli. J. Liaoning Univ. (Nat. Sci. Ed.) 2000, 3, 233-235.

[12] Zhang, Y. J; Li, X.; Li, X. L.; Wang, W.; Chen, Y. S. Nutritional components of the FlosPopuli. China Feed 1996, 3, 22-23.

[13] Zhao, Y.; Tang, G. S.; Hou, Y. Y.; Zhao, X. H; Lu, L.; Cai, E. B.; Zhang, L. X. J. Determination of amino acids in FlosPopuli Tomentosae by reversed phase high performance liquid chromatography. Food Saf. Qual. 2014, 7, 2192-2197.

[14] Li, L.; Zhou, H. P.; Wang, J. L. Anti-oxidation effect of ultrasonic extraction from FlosPopuli. Feed Res. 2016, 14, 51-55.

[15] Tang, G. S. Master Degree Dissertation, Analysis of chemical constituents of FlosPopuli, Study its Derivatives and Screening of Biological Activity. Jilin Agricultural University, Jilin, China, 2015.

[16] Guo, S. J.; Shan, J. X.; Wang, Y. P.; Dong, L.; Tang, S.Y.; Xu, Q. Q.; Yang, L. M.; Fu, S. J.; Shen, Z. Q. Associated Bacteriostasis Research of Coptidis Rhizoma-Folium Isatidis and Coptidis Rhizoma-Flos Poprli against Escherichia coli O2. Anim. Husb. Feed Sci. 2019, 11, 42-44.

[17] Geng, J.; Xiang, Z. Y.; Han, J. X.; Zhao, B. K. Research progress on antibacterial effect and mechanism of FlosPopuli. Hubei Anim. Sci. Vet. Med. 2017, 38, 13-15.

[18] Zhou, H. P.; Li, L.; Tang, Y.; Liu, Z.; Liu, X. J.; Guo, J. Study on preparation and bacteriostasis of ultrasonic extraction from FlosPopuli. Feed Res. 2015, 23, 55-58.

[19] Wang, S. B.; Wang, Q.; Song, H. X.; Ji, M. F.; Yang, H. F.; Yu, S. L.; Chen, X. L.; Chen, H. F.; Wang, D. D.; Zhang, L. Inhibitory effect of FlosPopuli extract on Escherichia coli isolated from swine in vitro. Heilongjiang J. Anim. Sci. Vet. Med. 2018, 10, 182-184.

[20] Chen, Y. Q.; Li, L.; Niu, J. W.; Wang, S. Q. Observation on the therapeutic effect of FlosPopuli extract on a case of vibrios hepatitis. Chin. J. Anim. Husb. Veter. Med. 2018, 12, 45-46.

[21] Li, J. L.; Li, B.; Liu, J. T. Antibacterial of Populus tomentosa extract on Escherichia coli and Salmonella isolated from primates. Sichuan Anim. Sci. Vet. Med. 2012, 39, 28-30.

[22] Xu, Q. Q.; Shen, Z. Q.; Wang, Y. Q.; Guo, S. J.; Li, F.; Wang, Y. P.; Zhou, C. F. Anti-diarrhoeal and anti-microbial activity of FlosPopuli (male inflorescence of Populus tomentosa Carr.) aqueous extracts. J. Ethnopharmacol. 2013, 148, 640-646.

[23] Wang, X.; Zhang, H. X.; Deng, Y. G.; Shi, X. G.; Liu, J. H. Effects of the Extract of Populus canadensis Moench. Male Anthotaxy on Antioxidation and Prevention of DNA Damage Caused by Hydroxyl Radical in vitro. Food Sci. 2005, 5, 216-219.

[24] Li, L. J. Effect of poplar flower different extracts on immune function in mice. Northeast Agric. Univ. 2013, 44, 86-89.

[25] Wang, Y. P.; Guo, S. J.; Dong, L.; Xu, Q. Q.; Mo, L.; Yang, L. M.; Zhang, Y.; Zhang, Z. M.; Shen, Z. Q. Inhibitory effect of water extract of male inflorescence of Populus tomentosa on microorganisms in livestock and poultry in vitro. Heilongjiang $\mathrm{J}$. Anim. Sci. Vet. Med. 2016, 10, 155-156.

[26] Zhao, Y.; Tang, G.; Cai, E.; Liu, S.; Zhang, L.; Wang, S. Hypolipidaemic and antioxidant properties of ethanol extract fromFlos populi. Natural Product Research. Nat. Prod. Res. 2014, 28, 1467-1470.

[27] Hou, Y.; Zhang, G.; Li, M.; Li, B.; Chen, L.; Tian, Y.; Dong, J. Antioxidant and anti-inflammatory constituents from FlosPopuli. Nat. Prod. Res. 2019, 3, 1-9.

[28] Fang, C. L.; Yang, G. Y.; Yang, H. H.; Li, C. Experiments on pharmacology of Populus tomentosa extracts and their compound preparations. J. Chin. Soc. Vet. Sci. 2010, 3, 205-209.

Received April 16, 2020 Accepted May 7, 2020 